\section{Patient hat Anspruch auf Negativauskunft}

§ 630c Abs. 2 S 2 BGB gewährt dem Patienten unter Umständen eine Negativauskunft. Damit hat er einen Anspruch auf die Erklärung des Behandlers, dass für inn keine Umstände erkennbar sind, welche die Annahme eines

Behandlungsfehlers begründen können. Gibt der Behandler eine entsprechende Erklärung erst in der mündlichen Verhandlung ab, ist regelmäßig eine Aufhebung der Kosten nach beiderseitiger Erledigungserklärung angemessen.

Oberlandesgericht Oldenburg

Urteil vom 25. August 2015 - 5 W 35/15

\section{Erstattung nur bei Heilpraktikern gemäß Heilpraktikergesetz}

Privat Krankenversicherte haben keinen Anspruch gegen ihre Krankenversicherung auf Erstattung von Aufwendungen für einen im Ausland tätigen Heilpraktiker, sofern dieser keine Erlaubnis nach $\S 1$ Abs. 1 Heilpraktikergesetz innehat.

Der Kläger hatte einen in Luxemburg tätigen Chiropraktiker mit chiropraktischen Leistungen beauftragt, der in Frankreich einen Doktor der Chiropraktik erworben hatte. Eine Erlaubnis nach dem deutschen Heilpraktikergesetz besaß er nicht. Die Versicherungsbedingungen der Beklagten sahen vor, dass nur Heilpraktiker im Sinne des deutschen Heilpraktikergesetzes in Anspruch genommen werden dürfen.

Heilpraktiker im Sinne des deutschen Heilpraktikergesetzes sind nur solche mit einer Erlaubnis nach $\S 1$ Abs. 1 Heilpraktikergesetz. Nicht maßgeblich sei, ob der als Heilpraktiker Tätige die Voraussetzungen zum Erhalt der Erlaubnis besitze. Es komme für die Erstattungsfähigkeit der Leistungen allein auf die formelle Inhaberschaft der Erlaubnis an

Der Kläger hat nach einem Hinweisbeschluss des Landgericht Trier (vom 14. September 2015 - 1 S 123/15) seine Berufung gegen das Urteil des Amtsgerichts Bitburg zurückgenommen.

Die Entscheidung ist damit rechtskräftig.

Amtsgerichts Bitburg,

Urteil vom 29. Juni 2015 - 5 C 390/14

\section{Arbeitnehmerrecht}

\section{Anspruch auf Freistellung zur Arbeitssuche}

\author{
Nach einer ordentlichen Kündigung haben Arbeitnehmer Anspruch auf \\ Freistellung von der Arbeit, um Vorstellungsgespräche wahrzunehmen.
}

E in angestellter Radiologe hatte sich nach einer ordentlichen Kündigung mehrmals für Vorstellungsgespräche freistellen lassen. Der Arbeitgeber hatte dies akzeptiert und keine näheren Informationen über Ort und Zeit der Gespräche verlangt. Dann kam es wegen diverser Punkte zum Streit: Ein Vorgesetzter hatte den Mann während einer Krankschreibung am Bahnhof gesichtet, angeblich hatte er auch kostenlose MRT-Untersuchungen an sich selbst durchgeführt. Man warf ihm nun vor, sich durch Vortäuschung von Terminen für Vorstellungsgespräche bezahlte Freizeit erschlichen zu haben. Es folgte die fristlose Kündigung. Der Arbeitnehmer ging dagegen gerichtlich vor.

\section{Das Urteil}

Das hessische Landesarbeitsgericht entschied, dass der Arbeitgeber nicht zur fristlosen Kündigung berechtigt gewesen sei. Es gebe keine konkreten Anhaltspunkte dafür, dass der Radiologe sich bezahlte Freizeit erschlichen habe. Der Arbeitgeber müsse keine Freistellung gewähren, wenn ihn der Mitarbeiter nicht zumindest über Ort und ungefähre Dauer der Vorstellungsgespräche informiere. Genehmige der Arbeitgeber die Freistellung ohne solche Informationen zu erfragen, könne er die fehlenden Details später nicht zum Nachteil des Arbeitnehmers auslegen und damit einen entsprechenden Verdacht begründen. Die Freistellung für Vorstellungsgespräche sei damit kein zulässiger Kündigungsgrund.

Nach einer ordentlichen Kündigung hat demnach ein Arbeitnehmer gemäß $\$ 629$ des BGB Anspruch auf Freistellung

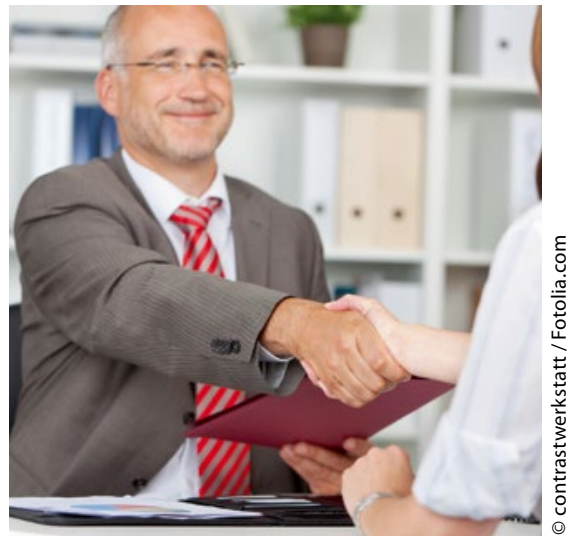

von der Arbeit für Vorstellungsgespräche. Der Arbeitnehmer muss eine angemessene Zeit für seine Bewerbungsgespräche erhalten - wie viel, ist nach Auffassung der Richter von Fall zu Fall unterschiedlich. Nach $₫ 616$ BGB ist der Arbeitnehmer für diese Zeit mit der normalen Vergütung zu bezahlen - zumindest, solange Tarif- oder Arbeitsvertrag nichts anderes besagen. Konkrete Angaben zum möglichen neuen Arbeitgeber müssen Betroffene beim alten Chef nicht machen.

Landesarbeitsgericht Hessen,

Urteil vom 28. November 2012 - 18 Sa 695/12

\section{Literatur beim Verfasser}

\section{Arno Zurstraßen M.A.}

Rechtsanwalt und Mediator im Gesundheitswesen

Fachanwalt für Medizinrecht und Fachanwalt für Sozialrecht Aachener Straße 197-199, 50931 Köln E-Mail:contact@arztundrecht.de www.arztundrecht.de 